\title{
SISTEM PENDUKUNG KEPUTUSAN PEMILIHAN PENGAJAR LES PRIVAT UNTUK SISWA LEMBAGA BIMBINGAN BELAJAR DENGAN METODE AHP (STUDI KASUS LBB SYSTEM CERDAS)
}

\author{
Lusiana Kristiyanti, Aris Sugiharto, Helmie Arif W \\ Ilmu Komputer / Informatika FSM Universitas Diponegoro \\ klusiana@yahoo.com, aris.sugiharto@undip.ac.id, helmie.arif@gmail.com
}

\begin{abstract}
ABSTRAK
Lembaga bimbingan belajar les privat adalah salah satu usaha yang sedang berkembang pesat. Banyak siswa yang ingin mendaftar les privat sehingga lembaga sering melakukan pemilihan pengajar untuk mengajar siswa. Proses pemilihan pengajar menjadi hal yang sangat penting agar siswa mendapatkan pengajar sesuai yang diinginkan. Oleh karena itu, perlu dibuat Sistem Pendukung Keputusan (SPK) yang dapat membantu lembaga dalam memilih pengajar agar lebih efisien dan efektif. Sistem dibangun menggunakan bahasa pemrograman PHP. Sistem ini menggunakan metode AHP yang mempunyai kemampuan untuk memecahkan masalah multikriteria. Kriteria yang menjadi pertimbangan dalam sistem pemilihan pengajar ini meliputi jenis kelamin siswa, jumlah jam mengajar pengajar setiap minggu, jumlah siswa yang diajar pengajar, masa kerja pengajar, jurusan pengajar serta semester pengajar. Setiap kriteria dibandingkan dengan nilai skala perbandingan Saaty agar mendapat nilai bobot untuk penilaian pengajar. Sistem yang dihasilkan dapat memberikan rangking pengajar berdasarkan nilai yang didapat pengajar sehingga dapat digunakan untuk pemilihan pengajar di lembaga bimbingan belajar.
\end{abstract}

Kata kunci: Sistem Pendukung Keputusan (SPK), Metode AHP , Pemilihan Pengajar.

\section{PENDAhuluan}

Sejalan dengan berkembangnya teknologi informasi, semakin bertambah pula kebutuhan tentang kemampuan komputer dalam membantu menyelesaikan permasalahan-permasalahan di berbagai bidang. Di antaranya sistem pendukung keputusan berbasis komputer, sistem ini adalah sistem berbasis komputer yang dirancang untuk membantu pengambil keputusan dalam memecahkan masalah baik yang terstruktur maupun tidak terstruktur dengan menggunakan data dan model. Penyusunan model keputusan dilakukan dengan cara mengembangkan hubungan-hubungan logis yang mendasari persoalan keputusan ke dalam suatu model matematis, yang mencerminkan hubungan yang terjadi di antara faktor-faktor yang terlibat.

Banyak metode yang dapat digunakan dalam sistem pendukung keputusan. Salah satu metode yang dapat digunakan adalah metode Analytical Hierarchy Process (AHP). Metode ini banyak digunakan untuk menyelesaikan permasalahan yang rumit. Hal ini disebabkan metode AHP memperhitungkan validasi nilai sampai dengan batas toleransi inkonsistensi berbagai kriteria, struktur AHP yang berhierarki serta metode AHP memperhitungkan daya tahan output analisis sensitivitas pengambilan keputusan. Beberapa permasalahan rumit yang telah diselesaikan dengan metode AHP, misalnya dalam penerimaan karyawan [1], penentuan prioritas usulan sertifikasi guru [2], penjadwalan trucking dan heavy equipment rental [3], dan penentuan mustahik [4].

Dewasa ini sistem pendukung keputusan pemilihan pengajar les privat yang mengajar siswa di Lembaga Bimbingan Belajar System Cerdas menjadi permasalahan yang cukup rumit. Lembaga Bimbingan Belajar System Cerdas merupakan salah satu lembaga bimbingan belajar les privat yang terletak di Perum Bukit Diponegoro C 229 kecamatan Tembalang, kota Semarang. Lembaga ini berdiri pada tahun 2007. Lembaga ini kurang lebih memiliki 60 pengajar.

Sebuah lembaga bimbingan belajar les privat tentunya memerlukan sebuah manajemen yang baik dalam menentukan pengajar yang mengajar siswa yang hendak les privat di lembaga dari sekian banyak pilihan pengajar yang bekerja di lembaga tersebut. Pilihan pengajar ini akan sangat berpengaruh terhadap tingkat kepuasan siswa dalam les privat ini. Jika siswa merasa puas tentunya akan membuat nama Lembaga System Cerdas menjadi baik di masyarakat. 
Banyak pertimbangan yang dipikirkan Lembaga System Cerdas dalam pemilihan pengajar ini, seperti kesediaan waktu pengajar, kemampuan akademik pengajar, jumlah jam mengajar pengajar setiap minggu, kemampuan mengajar pengajar serta faktor pertimbangan lain yang mendukung pemilihan pengajar ini.

Lembaga Bimbingan Belajar System Cerdas dalam menentukan pilihan pengajar ini masih secara manual, belum menggunakan sistem yang terkomputerisasi sehingga membutuhkan waktu yang cukup lama dalam menentukan pengajar ketika ada siswa baru yang mendaftar les di lembaga.

\section{DASAR TEORI}

\subsection{Pengertian Sistem Pendukung Keputusan}

Konsep Sistem Pendukung Keputusan (SPK) pertama kali diungkap pada tahun 1970an oleh Michael S.Scott Morton dengan istilah Management Decision System.

SPK merupakan sistem informasi interaktif yang menyediakan informasi, pemodelan, dan pemanipulasian data. Menurut Alter, SPK digunakan untuk membantu pengambilan keputusan dalam situasi semiterstruktur dan situasi tidak terstruktur yang mana tak seorang pun tahu secara pasti bagaimana keputusan seharusnya dibuat [5]. SPK adalah suatu bentuk Computer Base Information System (CBIS) yang interaktif, fleksibel, dan secara khusus dikembangkan untuk mendukung penyelesaian masalah dari manajemen yang tidak terstruktur untuk memperbaiki pembuatan keputusan [6].

SPK biasanya dibangun untuk mendukung solusi atas suatu masalah atau untuk mengevaluasi suatu peluang. SPK tidak dimaksudkan untuk mengotomatisasikan pengambilan keputusan, tetapi memberikan perangkat interaktif yang memungkinkan pengambil keputusan untuk melakukan berbagai analisis menggunakan model-model yang tersedia.

\subsection{Multi Criteria Decision Making}

Multiple Criteria Decision Making (MCDM) adalah suatu model pengambilan keputusan untuk menetapkan alternatif terbaik dari sejumlah alternatif berdasarkan beberapa kriteria tertentu.

Ada beberapa fitur umum yang akan digunakan dalam MCDM [7], yaitu:

1. Alternatif; alternatif adalah obyek-obyek yang berbeda dan memiliki kesempatan yang sama untuk dipilih oleh pengambil keputusan.

2. Atribut; atribut sering disebut sebagai karakteristik, komponen atau kriteria keputusan.

3. Konflik antar kriteria; beberapa kriteria biasanya mempunyai konflik antara satu dengan yang lainnya, misalnya kriteria keuntungan akan mengalami konflik dengan kriteria biaya.

4. Bobot keputusan; bobot keputusan menunjukkan kepentingan relatif dari setiap kriteria, $\mathrm{W}=\left(\mathrm{w}_{1}, \mathrm{w}_{2}, \ldots, \mathrm{w}_{\mathrm{n}}\right)$.

5. Matriks keputusan; suatu matriks keputusan $\mathrm{X}$ yang berukuran $\mathrm{m} \times \mathrm{n}$, berisi elemenelemen $\mathrm{x}_{\mathrm{ij}}$, yang merepresentasikan rating dari alternatif $\mathrm{A}_{\mathrm{i}} \quad(\mathrm{i}=1,2, \ldots, \mathrm{m})$ terhadap kriteria $C_{j}(j=1,2, \ldots, n)$.

\subsection{Metode Analytic Hierarchy Process (AHP)}

Salah satu metode dalam model MADM untuk menyelesaikan masalah multikriteria adalah Analytic Hierarchy Process (AHP). AHP yang dikembangkan oleh Tomas L. Saaty merupakan model hierarki fungsional dengan input utamanya adalah persepsi manusia. Dengan adanya hierarki, masalah yang kompleks atau tidak terstruktur dipecah dalam sub-sub masalah kemudian disusun menjadi suatu bentuk hierarki. AHP mempunyai kemampuan untuk memecahkan masalah multi kriteria yang berdasar pada perbandingan preferensi dari setiap elemen dalam hierarki. Secara spesifik, AHP cocok digunakan untuk permasalahaan pemilihan kandidat ataupun pengurutan prioritas yang memiliki sifat-sifat sebagai berikut [8]:

a. Melibatkan kriteria-kriteria kualitatif yang sulit dikuantitatifkan secara eksak.

b. Masing-masing kriteria dapat memiliki subsub kriteria yang dapat dibentuk seperti hierarki.

c. Penilaian dapat dilakukan oleh satu atau beberapa pengambil keputusan secara sekaligus. 
d. Kandidat pilihan sudah tertentu dan terbatas jumlahnya.

\section{ANALISIS DAN DESAIN SISTEM 3.1. Analisis Sistem}

SPK pemilihan pengajar ini adalah sistem yang berfungsi untuk membantu administrator mengambil keputusan berupa pemberian saran pilihan pengajar yang terdaftar di Lembaga Bimbingan Belajar System Cerdas berdasarkan kriteria-kriteria yang telah ditentukan. Sistem ini membantu lembaga agar dapat memilih pengajar yang terbaik dengan lebih efektif dan efisien. Data yang diolah menjadi kriteria pemilihan diperoleh dari masukan administrator lembaga. Administrator memasukkan jadwal KBM siswa yang akan les, jenis kelamin siswa, dan mata pelajaran yang akan siswa pelajari. Data masukan tersebut diproses sebagai kriteria pemilihan untuk menghasilkan keputusan pengajar terbaik.

Data pengajar yang ada di basis data sebelum diproses dengan metode AHP dilakukan penyaringan data terlebih dahulu berdasarkan jumlah jam mengajar pengajar, kemampuan pengajar, jadwal pengajar. Data yang diproses harus dipastikan bahwa jumlah jam mengajar pengajar masih di bawah kuota maksimal kegiatan belajar mengajar yaitu kurang dari 15 pertemuan/minggu, pengajar mampu mengajar pelajaran sesuai spesifikasi yang diminta siswa, jumlah siswa yang diajar pengajar kurang dari 10 siswa serta pengajar tidak mempunyai jadwal mengajar saat waktu les yang diminta siswa. Data pengajar yang telah difilter ini baru dilakukan proses pemilihan dengan metode AHP.

Salah satu contoh kasus yang diselesaikan oleh SPK yang dibuat dengan metode AHP, misalnya ada seorang siswa perempuan kelas 2 SMA mendaftar les privat di lembaga dan ingin les mata pelajaran fisika hari selasa sore. Pihak lembaga memilih pengajar untuk mengajar siswa tersebut. Lembaga memilih pengajar dari data pengajar yang tersaji pada tabel 1 .
Tabel 1. Data Pengajar

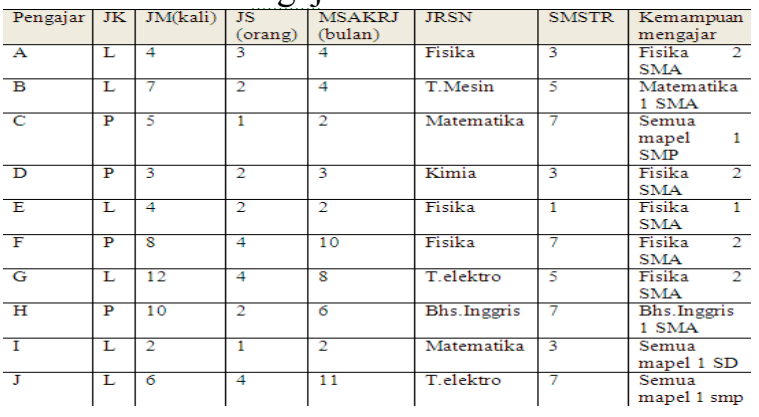

Tabel 2. Jadwal Pengajar

\begin{tabular}{|l|l|}
\hline Pengajar & \multicolumn{1}{|c|}{ Jadwal les } \\
\hline A & Senin sore, Kamis sore, Jumat sore, Jumat malam \\
\hline B & $\begin{array}{l}\text { Selasa sore, Selasa malam, Rabu sore, Rabu malam, Jumat } \\
\text { sore, Minggu pagi, Minggu malam }\end{array}$ \\
\hline C & $\begin{array}{l}\text { Senin malam, Rabu sore, Kamis malam, Jumat malam, Sabtu } \\
\text { malam }\end{array}$ \\
\hline D & Senin malam, Selasa sore, Rabu malam \\
\hline E & Kamis malam, Jumat sore, Jumat malam, Sabtu malam \\
\hline F & $\begin{array}{l}\text { Senin sore, Selasa malam, Rabu sore, Rabu malam, Kamis } \\
\text { malam, Jumat sore, Sabtu malam, Minggu pagi }\end{array}$ \\
\hline G & $\begin{array}{l}\text { Senin sore, Senin malam, Selasa malam, Rabu sore, Rabu } \\
\text { malam, Kamis sore, Kamis malam, Jumat sore, Sabtu sore, } \\
\text { Sabtu malam, Minggu pagi, Minggu malam }\end{array}$ \\
\hline H & $\begin{array}{l}\text { Senin sore, Senin malam, Selasa malam, Rabu sore, Kamis } \\
\text { sore, Kamis malam, Jumat malam, Sabtu sore, Minggu pagi, } \\
\text { Minggu malam }\end{array}$ \\
\hline I & Jumat malam, Minggu malam \\
\hline J & $\begin{array}{l}\text { Rabu sore, Rabu malam, Kamis sore, Kamis malam, Minggu } \\
\text { pagi, Minggu malam }\end{array}$ \\
\hline
\end{tabular}

Pemilihan pengajar diproses dengan metode AHP. Sebelum dilakukan pemrosesan dengan metode AHP, pengajar yang menjadi kandidat difilter terlebih dahulu. Pengajar yang menjadi pilihan adalah pengajar yang mempunyai kemampuan mengajar fisika kelas 2 SMA serta pengajar yang tidak mempunyai jadwal pada hari selasa sore selain itu juga jumlah jam mengajar pengajar yang masih di bawah 15 kali pertemuan serta pengajar yang masih mengajar siswa di bawah 10 orang siswa. Dari ketentuan tersebut maka pengajar yang diproses dengan metode AHP adalah pengajar A, F, dan G. Kriteria yang dipertimbangkan oleh lembaga adalah jenis kelamin, jumlah jam mengajar tiap minggu, jumlah siswa, masa kerja, jurusan, dan semester. Langkah-langkah yang dilakukan untuk menentukan pengajar yang paling tepat mengajar siswa tersebut adalah sebagai berikut :

1. Menentukan prioritas kriteria

Langkah yang harus dilakukan dalam menentukan prioritas kriteria adalah sebagai berikut : 
a. Membuat matriks perbandingan berpasangan Pada tahap ini dilakukan penilaian perbandingan antara satu kriteria dengan kriteria yang lain. Hasil penilaian dapat dilihat dalam tabel 3.

Tabel 3. Matriks Perbandingan Berpasangan

\begin{tabular}{|c|c|c|c|c|c|c|}
\hline & $\pi \mathrm{K}$ & $\mathbb{M}$ & JS & MSAKR & $\begin{array}{c}\text { JRS } \\
\mathrm{N}\end{array}$ & SMSTR \\
\hline KK & 1 & $1 / 2$ & $1 / 2$ & 4 & 3 & 4 \\
\hline MN & 2 & 1 & 2 & 5 & 4 & 4 \\
\hline JS & 2 & $1 / 2$ & 1 & 4 & 4 & 3 \\
\hline MSAKR & $1 / 4$ & $1 / 5$ & $1 / 4$ & 1 & 2 & 3 \\
\hline JRSN & $1 / 3$ & $1 / 4$ & $1 / 4$ & $1 / 2$ & 1 & 2 \\
\hline SMSTR & $1 / 4$ & $1 / 4$ & $1 / 3$ & $1 / 3$ & $1 / 2$ & 1 \\
\hline Jumlah & 5.83 & 2.7 & 4.33 & 14.83 & 14.5 & 17 \\
\hline
\end{tabular}

b. Membuat matriks nilai kriteria

Matriks ini diperoleh dengan rumus berikut :

Nilai baris kolom baru = Nilai baris kolom lama/jumlah masing-masing kolom lama.

Hasil perhitungan dapat dilihat dalam tabel 4 .

Tabel 1. Matriks Nilai Kriteria

\begin{tabular}{|l|l|l|l|l|l|l|l|l|} 
& JK & JM & JS & $\begin{array}{l}\text { MSA } \\
\text { KRJ }\end{array}$ & JRSN & SMSTR & Jumlah & Priontas \\
\hline JK & 0.17 & 0.19 & 0.12 & 0.27 & 0.21 & 0.24 & 1.2 & 0.2 \\
\hline JM & 0.34 & 0.37 & 0.46 & 0.34 & 0.28 & 0.24 & 2.03 & 0.34 \\
\hline JS & 0.34 & 0.19 & 0.23 & 0.27 & 0.28 & 0.18 & 1.49 & 0.25 \\
\hline MSAKRJ & 0.04 & 0.07 & 0.06 & 0.07 & 0.14 & 0.18 & 0.56 & 0.09 \\
\hline JRSN & 0.06 & 0.09 & 0.06 & 0.03 & 0.07 & 0.12 & 0.43 & 0.07 \\
\hline SMSTR & 0.04 & 0.09 & 0.08 & 0.02 & 0.03 & 0.06 & 0.32 & 0.05 \\
\hline
\end{tabular}

c. Membuat matriks penjumlahan setiap baris

Matriks ini dibuat dengan mengalikan nilai prioritas pada tabel 4 dengan matriks perbandingan berpasangan pada tabel 3 Hasil perhitungan disajikan dalam tabel 5 .

Tabel 2 Matriks Penjumlahan Setiap Baris

\begin{tabular}{|l|l|l|l|l|l|l|l|}
\hline & $\mathbb{K}$ & $\mathbb{M}$ & JS & MSAKRJ & IRSN & SMSTR & Jumlah \\
\hline JK & 0.2 & 0.17 & 0.13 & 0.36 & 0.21 & 0.2 & 1.27 \\
\hline $\mathbb{M}$ & 0.4 & 0.34 & 0.5 & 0.45 & 0.28 & 0.2 & 2.17 \\
\hline JS & 0.4 & 0.17 & 0.25 & 0.36 & 0.28 & 0.15 & 1.61 \\
\hline MSAKRJ & 0.05 & 0.07 & 0.06 & 0.09 & 0.14 & 0.15 & 0.56 \\
\hline JRSN & 0.07 & 0.09 & 0.06 & 0.05 & 0.07 & 0.1 & 0.44 \\
\hline SNSTR & 0.05 & 0.09 & 0.08 & 0.03 & 0.04 & 0.05 & 0.34 \\
\hline
\end{tabular}

Kolom jumlah per baris diperoleh dari kolom jumlah pada tabel 5, sedangkan kolom prioritas diperoleh dari kolom prioritas pada tabel 4.

d. Penghitungan rasio konsistensi

Penghitungan ini digunakan untuk memastikan bahwa nilai rasio konsistensi $(\mathrm{CR})<=0.1$. Jika ternyata nilai $\mathrm{CR}$ lebih besar dari 0.1 maka matriks perbandingan berpasangan harus diperbaiki. Untuk menghitung rasio konsistensi, dibuat tabel seperti terlihat dalam tabel 6 .

Tabel 6. Perhitungan Rasio Konsistensi

\begin{tabular}{|l|l|l|l|}
\hline & Jumlah per baris & Prionitas & Hasil \\
\hline JK & 1.27 & 0.2 & 6.35 \\
\hline JM & 2.17 & 0.34 & 6.38 \\
\hline JS & 1.61 & 0.25 & 6.44 \\
\hline MSAKRJ & 0.56 & 0.09 & 6.22 \\
\hline JRSN & 0.44 & 0.07 & 6.29 \\
\hline SMSTR & 0.34 & 0.05 & 6.80
\end{tabular}

Dari tabel 6, diperoleh nilai-nilai sebagai berikut :

Jumlah (jumlahan dari nilai-nilai hasil) : 38.48

n (jumlah kriteria) : 6

$\lambda$ maks (jumlah/n) $: 6.41$

CI $((\lambda$ maks-n $) / n): 0.07$

CR (CI/IR) : 0.06

Oleh karena $\mathrm{CR}<0.1$, maka rasio konsistensi dari perhitungan tersebut bisa diterima.

2. Menentukan prioritas subkriteria. Penghitungan subkriteria dilakukan terhadap sub-sub dari kriteria Jumlah jam mengajar tiap minggu (JM) dan jumlah siswa (JS).

i. Menghitung prioritas subkriteria dari kriteria JM.

Langkah-langkah yang dilakukan untuk menghitung prioritas subkriteria dari kriteria JM adalah sebagai berikut :

a. Membuat matriks perbandingan berpasangan. Hasilnya ditunjukkan dalam tabel 7.

Tabel 3 Matriks Perbandingan Berpasangan Kriteria JM

\begin{tabular}{|l|l|l|l}
\hline & Padat & Sering & Jarang \\
\hline Padat & 1 & $1 / 3$ & $1 / 5$ \\
\hline Sering & 3 & 1 & $1 / 3$ \\
\hline Jarang & 5 & 3 & 1 \\
\hline Jumlah & 9 & 4.33 & 1.53
\end{tabular}

b. Membuat matriks nilai kriteria.

Hasilnya ditunjukkan dalam tabel 8 .

Tabel 4 Matriks Nilai Kriteria JM

\begin{tabular}{|l|l|l|l|l|l|l|}
\hline & Padat & Sering & Jarang & Jumlah & Pionitas & $\begin{array}{l}\text { Prioritas } \\
\text { Subkriteria }\end{array}$ \\
\hline Padat & 0.11 & 0.08 & 0.13 & 0.32 & 0.11 & 0.17 \\
\hline Sering & 0.33 & 0.23 & 0.22 & 0.78 & 0.26 & 0.41 \\
\hline Jarang & 0.56 & 0.69 & 0.65 & 1.90 & 0.63 & 1 \\
\hline
\end{tabular}


Nilai pada kolom prioritas subkriteria diperoleh dari nilai prioritas pada baris tersebut dibagi dengan nilai tertinggi pada kolom prioritas.

c. Menentukan matriks penjumlahan setiap baris.

Setiap elemen dalam tabel 9 dihitung dengan mengalikan matriks perbandingan berpasangan dengan nilai prioritas.

Tabel 9. Matriks Penjumlahan Setiap Baris Kriteria JM

\begin{tabular}{|l|l|l|l|l|}
\hline & Padat & Sering & Jarang & Jumlah \\
\hline Padat & 0.11 & 0.09 & 0.13 & 0.33 \\
\hline Sering & 0.33 & 0.26 & 0.21 & 0.80 \\
\hline Jarang & 0.55 & 0.78 & 0.63 & 1.96 \\
\hline
\end{tabular}

d. Penghitungan rasio konsistensi.

Untuk menghitung rasio konsistensi, dibuat tabel 10 .

Tabel 10. Penghitungan Rasio Konsistensi Kriteria JM

\begin{tabular}{|l|l|l|l|}
\hline & Jumlah perbanis & Priontas & Hasil \\
\hline Padat & 0.33 & 0.11 & 3 \\
\hline Sering & 0.80 & 0.26 & 3.08 \\
\hline Jarang & 1.96 & 0.63 & 3.11 \\
\hline
\end{tabular}

Jumlah (jumlahan dari nilai-nilai hasil) : 9.19 $\mathrm{n}$ (jumlah kriteria) : 3

$\lambda$ maks (jumlah/n) : 3.06

CI $((\lambda$ maks-n $) / \mathrm{n}): 0.02$

$\mathrm{CR}(\mathrm{CI} / \mathrm{IR}): 0.03$

ii. Menghitung prioritas subkriteria dari kriteria JS.

Langkah-langkah yang dilakukan untuk menghitung prioritas subkriteria dari kriteria JS adalah sebagai berikut :

a. Membuat matriks perbandingan berpasangan.

Hasilnya disajikan dalam tabel 11.

Tabel 11. Matriks Perbandingan Berpasangan Kriteria JS

\begin{tabular}{|l|l|l|l|}
\hline & Banyak & Sedang & Sedikit \\
\hline Banyak & 1 & $1 / 3$ & $1 / 7$ \\
\hline Sedang & 3 & 1 & $1 / 5$ \\
\hline Sedikit & 7 & 5 & 1 \\
\hline Jumlah & 11 & 6.33 & 1.34 \\
\hline
\end{tabular}

b. Membuat matriks nilai kriteria.

Hasilnya terlihat dalam tabel 12 .

Tabel 12. Matriks Nilai Kriteria JS

\begin{tabular}{|l|l|l|l|l|l|l|}
\hline & Banyak & Sedang & Sedikit & Jumlah & Phonitas & $\begin{array}{l}\text { Prioritas } \\
\text { Subbriteria }\end{array}$ \\
\hline Banyak & 0.09 & 0.05 & 0.10 & 0.24 & 0.08 & 0.11 \\
\hline Sedang & 0.27 & 0.16 & 0.15 & 0.58 & 0.19 & 0.26 \\
\hline Sedikit & 0.64 & 0.79 & 0.75 & 2.18 & 0.73 & 1 \\
\hline
\end{tabular}

c. Menentukan matriks penjumlahan setiap baris.

Hasilnya disajikan dalam tabel 13.

Tabel 13. Matriks Penjumlahan Setiap Baris Kriteria JS

\begin{tabular}{|l|l|l|l|l|}
\hline & Banyak & Sedang & Sedikit & Jumlah \\
\hline Banyak & 0.08 & 0.06 & 0.10 & 0.24 \\
\hline Sedang & 0.24 & 0.19 & 0.15 & 0.58 \\
\hline Sedikit & 0.56 & 0.95 & 0.73 & 2.24 \\
\hline
\end{tabular}

d. Penghitungan rasio konsistensi.

Untuk menghitung rasio konsistensi dibuat tabel 14.

Tabel 14. Penghitungan Rasio Konsistensi Kriteria JS

\begin{tabular}{|l|l|l|l|}
\hline & Jumlah perbaris & Priontas & Hasil \\
\hline Banyak & 0.24 & 0.08 & 3 \\
\hline Sedang & 0.58 & 0.19 & 3.05 \\
\hline Sedikit & 2.24 & 0.73 & 3.07 \\
\hline
\end{tabular}

Dari tabel 14, diperoleh nilai-nilai sebagai berikut :

Jumlah (jumlahan dari nilai-nilai hasil) : 9.12

n (jumlah kriteria) : 3

$\lambda$ maks (jumlah/n) $: 3.04$

CI $((\lambda$ maks-n $) / n): 0.01$

$\mathrm{CR}(\mathrm{CI} / \mathrm{IR}): 0.02$

3. Menghitung hasil

Prioritas hasil perhitungan pada langkah 1 dan 2 kemudian dituangkan dalam matriks hasil yang terlihat dalam tabel 15 . 
Tabel 15. Matriks Hasil

\begin{tabular}{|l|l|l|l|l|l|}
\hline JK & JM & JS & MSAKRJ & JRSN & SMSTR \\
\hline 0.2 & 0.34 & 0.25 & 0.09 & 0.07 & 0.05 \\
\hline- & Padat & Banyak & - & - & - \\
\hline- & 0.17 & 0.11 & - & - & - \\
\hline- & Sering & Sedang & - & - & - \\
\hline- & 0.41 & 0.26 & - & - & - \\
\hline- & Jarang & Sedikit & - & - & - \\
\hline- & 1 & 1 & - & - & - \\
\hline
\end{tabular}

Data Pengajar yang diproses dengan metode AHP dapat dilihat dalam tabel 16.

Tabel 16. Data Pengajar yang Diproses dengan AHP

\begin{tabular}{|l|l|l|l|ll|l|l|}
\hline Pengajar & JK & JM & JS & MSAKR & JRSN & SMSTR \\
\hline A & L & 4 & 3 & 4 & Fisika & 3 \\
\hline F & P & 8 & 4 & 10 & Fisika & 7 \\
\hline G & L & 12 & 4 & 8 & TElektro & 5 \\
\hline
\end{tabular}

Kriteria jenis kelamin (JK) diubah menjadi nilai 1 jika jenis kelamin pengajar sama dengan jenis kelamin siswa yang diajar pengajar serta diubah menjadi nilai 0 jika jenis kelamin pengajar berbeda dengan jenis kelamin siswa.

Kriteria jumlah jam mengajar (JM) mempunyai 3 subkriteria, yaitu padat, sering, dan jarang. Penilaian termasuk padat jika nilai JM lebih dari 8 , termasuk sering jika nilai JM lebih dari 5 dan kurang dari atau sama dengan 8 serta termasuk jarang jika nilai JM kurang dari atau sama dengan 5 .

Kriteria jumlah siswa (JS) mempunyai 3 subkriteria, yaitu banyak, sedang, dan sedikit. Penilaian termasuk banyak jika nilai JS lebih dari 5 , termasuk sedang jika nilai JS lebih dari 3 dan kurang dari atau sama dengan 5 serta termasuk sedikit jika nilai JS kurang dari atau sama dengan 3 .

Kriteria jurusan diubah menjadi nilai 1 jika jurusan pengajar sesuai dengan mata pelajaran yang diajarkan kepada siswa yang diajar serta bernilai 0 jika sebaliknya.

Hasil akhir perhitungan data pengajar pada Tabel 16 dengan AHP disajikan dalam tabel 17.
Tabel 17. Hasil Akhir

\begin{tabular}{|l|l|l|l|l|l|l|l|}
\hline Pengajar & JK & $\mathbb{N}$ & JS & MSAKRJ & JRSN & SMSTR & Total \\
\hline F & 0.2 & 0.14 & 0.07 & 0.9 & 0.07 & 0.35 & 1.73 \\
\hline A & 0 & 0.34 & 0.25 & 0.36 & 0.07 & 0.15 & 1.17 \\
\hline G & 0 & 0.06 & 0.07 & 0.72 & 0 & 0.25 & 1.1 \\
\hline
\end{tabular}

Nilai total ini yang dipakai sebagai dasar untuk merangking pengajar yang disarankan untuk mengajar siswa. Semakin besar nilainya, pengajar tersebut akan semakin disarankan untuk mengajar siswa.

\subsection{Desain Antarmuka}

Struktur menu SPK Pemilihan Pengajar yang dibuat dapat dilihat pada gambar 1 .

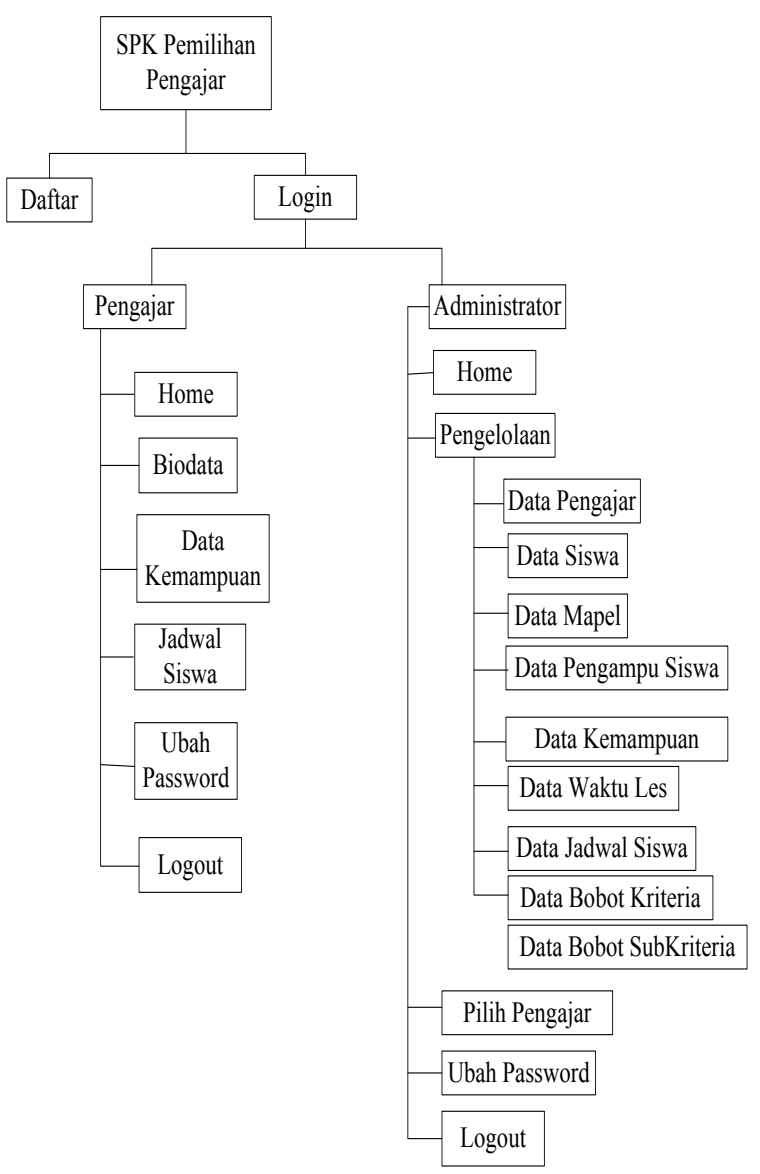

Gambar 1. Struktur Menu SPK yang dibuat 


\subsubsection{Desain Antarmuka Menu Data Bobot Kriteria}

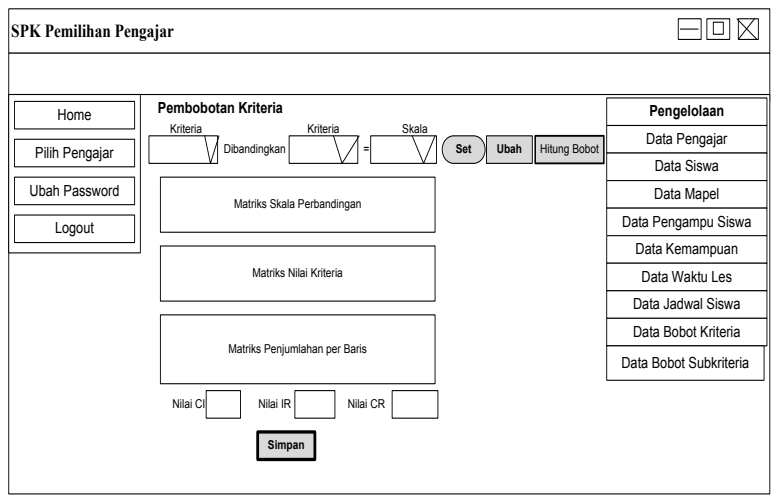

Gambar 2. Desain Menu Data Bobot Kriteria

\subsubsection{Desain Antarmuka Menu Data Bobot Subkriteria}

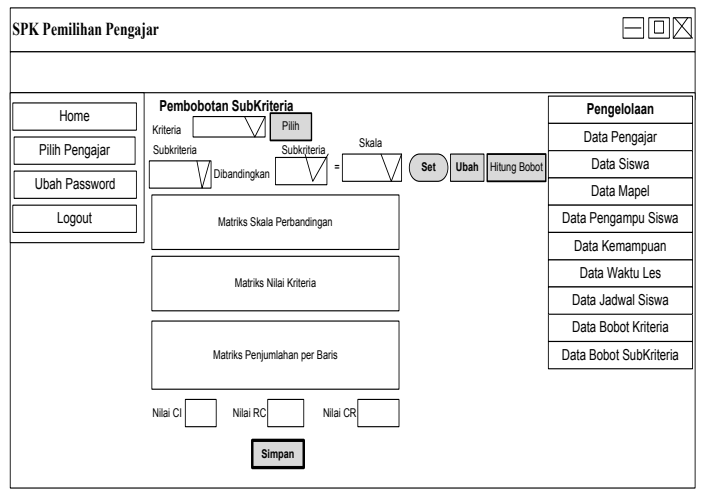

Gambar 3. Desain Menu Data Bobot Subkriteria

\subsubsection{Desain Antarmuka Menu Pilih Pengajar}

Menu ini merupakan menu yang digunakan untuk memilih pengajar.

\begin{tabular}{|c|c|c|}
\hline \multicolumn{2}{|c|}{ SPK Pemilihan Pengajar } & $\square \square \bigotimes$ \\
\hline Home & \multirow{4}{*}{$\begin{array}{l}\text { SISWA YANG AKAN LES } \\
\text { Jenis Kelamin: } \bigcirc \mathrm{L} \quad \mathrm{P}^{\mathrm{P}} \\
\text { Waktu Les: Hari } \square \text { Wakku }\end{array}$} & Pengelolaan \\
\hline Pilih Pengajar & & Data Pengajar \\
\hline \multirow{2}{*}{ Ubah Password } & & Data Siswa \\
\hline & & Data Mapel \\
\hline \multirow[t]{6}{*}{ Logout } & & Data Pengampu Siswa \\
\hline & Mapel: & Data Kemampuan \\
\hline & & Data Waktu Les \\
\hline & Pilih Pengajar & Data Jadwal Siswa \\
\hline & & Data Bobot Kriteria \\
\hline & & Data Bobot SubKriteria \\
\hline
\end{tabular}

Gambar 4. Desain Menu Pilih Pengajar
Hasil Pemilihan pengajar dari menu pilih pengajar dapat dilihat pada gambar 5 .

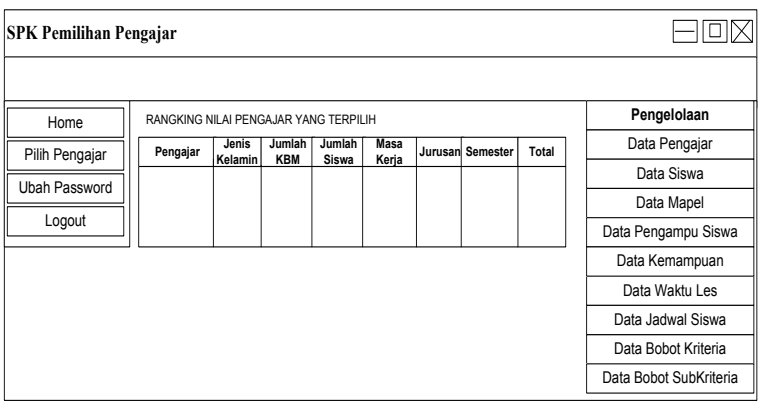

Gambar 5. Desain Hasil Pemilihan Pengajar

\section{IMPLEMENTASI DAN PENGUJIAN}

4.1. Implementasi Antarmuka

4.1.1. Implementasi Menu Data Bobot Kriteria

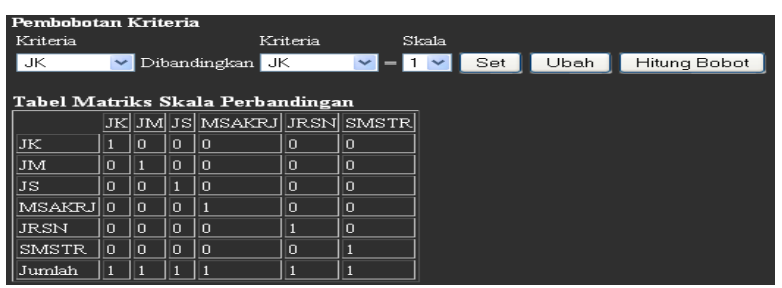

Gambar 6. Tampilan Menu Data Bobot Kriteria

\subsubsection{Implementasi Menu Data Bobot Subkriteria}

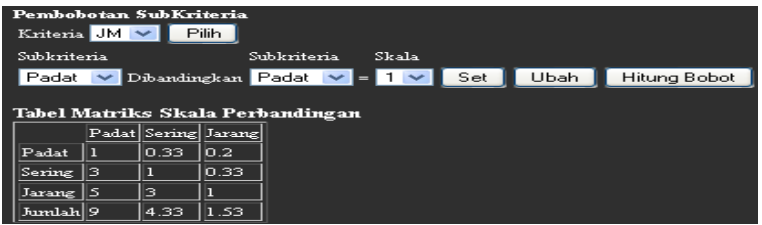

Gambar 7. Tampilan Menu Data Bobot Subkriteria

\subsubsection{Implementasi Menu Pilih Pengajar}

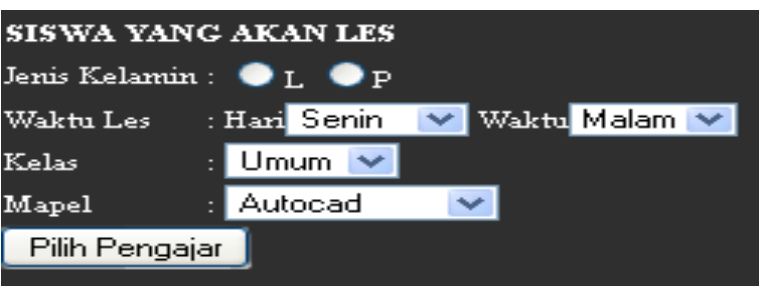

Gambar 8. Tampilan Menu Pilih Pengajar

Tampilan hasil pemilihan pengajar disajikan pada gambar 9 . 


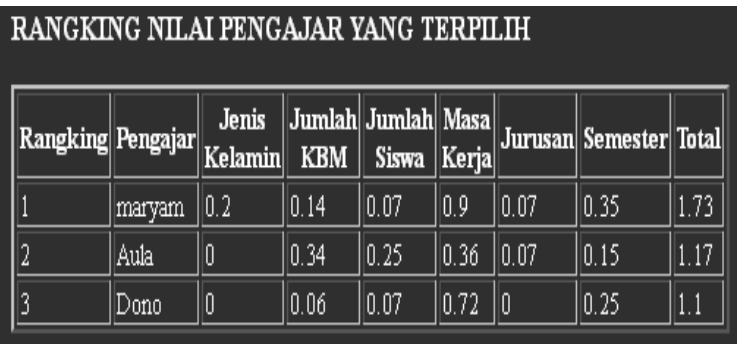

Gambar 9. Tampilan Hasil Pemilihan Pengajar

\subsection{Pengujian Sistem}

\subsubsection{Lingkungan Pengujian}

\subsubsection{Perangkat Keras}

Perangkat keras yang digunakan untuk pengujian SPK Pemilihan Pengajar Menggunakan Metode AHP adalah sebagai berikut :

1. System Manufacturer : Acer

2. System Model : Aspire $4730 \mathrm{z}$

3. Processor: Pentium(R) Dual-Core CPU

4. Memory: $954 \mathrm{MB}$ RAM

5. DirectX Version : 9.0c (4.09.0000.0904)

\subsubsection{Perangkat Lunak}

Perangkat lunak yang digunakan untuk menguji SPK Pemilihan Pengajar Menggunakan Metode AHP adalah sebagai berikut :

1. Sistem Operasi : Microsoft Windows XP Profesional

2. DBMS : MySQL client versi 5.1.37

3. Browser : Mozilla Firefox versi 16.0.2.4680

4. XAMPP versi 1.7.2.

\subsubsection{Analisis Hasil Pengujian}

Dari hasil pengujian dapat diketahui bahwa sistem ini telah memenuhi untuk :

1. Dapat melakukan Autentikasi pengguna.

2. Dapat memanajemen data lembaga yang terdiri atas data pengajar, data siswa, data jadwal les siswa, data pengampu siswa, data perhitungan AHP.

3. Dapat memasukkan biodata pengajar, Jadwal les siswa yang diajar pengajar, data kemampuan pengajar.

4. Dapat memfilter data pengajar berdasarkan kriteria pemilihan.

5. Dapat melakukan pemilihan pengajar dengan metode AHP.

\section{KESIMPULAN DAN SARAN}

\subsection{Kesimpulan}

Kesimpulan yang dapat diambil dari pembuatan tugas akhir ini adalah sebagai berikut:

1. Telah dihasilkan sebuah sistem pendukung keputusan pemilihan pengajar dengan metode AHP.

2. Sistem pendukung keputusan ini dapat digunakan untuk proses pemilihan pengajar yang lebih efisien dan efektif dibanding sistem yang belum terkomputerisasi.

\subsection{Saran}

Beberapa saran untuk pengembangan sistem pendukung keputusan pemilihan pengajar yang diharapkan dapat diimplementasikan adalah sebagai berikut :

1. Sistem dapat mengubah kriteria pemilihan pengajar sesuai kebutuhan pengguna.

2. Sistem dapat menambah sub kriteria dari kriteria pemilihan pengajar.

\section{DAFTAR PUSTAKA}

[1] Hafsarah R., Syukur A., dan Catur T,"Penerapan Metode AHP dalam Penerimaan Karyawan pada PT. Pasir Besi Indonesia", diakses dari http://www.research.pps.dinus.ac.id, tanggal 10 Januari 2012, pukul 13.00 WIB.

[2] Rochmasari L., Suprapedi, dan Subagyo H, "Penentuan Prioritas Usulan Sertifikasi Guru dengan Metode AHP", diakses dari http://www.research.pps.dinus.ac.id, tanggal 10 Januari 2012, pukul 13.00 WIB.

[3] Setiawan A., Christian H., dan Kirana L, "Implementasi Sistem Penjadwalan Trucking dan Heavy Equipment Rental dengan Menggunakan AHP", diakses dari http://www.repository.upnyk.ac.id, tanggal 10 Januari 2012, pukul 13.10 WIB.

[4] Subri, Ahmad, "Rancang Bangun Sistem Penunjang Keputusan Penentuan Mustahik", diakses dari http://www.scribd.com, tanggal 10 Januari 2012, pukul 14.00 WIB. 
[5] Kusrini, 2007, "Konsep dan Aplikasi Sistem Pendukung Keputusan", Andi, Yogyakarta.

[6] Turban, E, 2005, "Decision Support System and Intelligent System (Sistem Pendukung Keputusan dan Sistem Cerdas)", Andi, Yogyakarta.

[7] Kusumadewi, S, dkk., 2006, "Fuzzy MultiAttribute Decision Making (Fuzzy MADM)", Graha Ilmu, Yogyakarta.

[8] Komarudin, "Analytic Hierarchy Process $(A H P)$ ", diakses dari http://www.heru.wordpress.com, tanggal 20 Agustus 2011, pukul 15.00 WIB.

[9] Pressman, Roger S, 2001, "Software Engineering : A Practitioner's approach", McGraw - Hill, New York.

[10] Widodo, A.P., dkk, 2004, "Buku Ajar Basis Data", Jurusan Matematika Fakultas MIPA Universitas Diponegoro, Semarang.

[11] Al Bahra Bin Ladjamudin B, 2006, "Rekayasa Perangkat Lunak", Graha Ilmu, Yogyakarta.

[12] Widodo, A.P., dkk, 2006, "Bahan Ajar Pemrograman Internet", Jurusan Matematika Fakultas MIPA Universitas Diponegoro, Semarang.

[13] Simarmata, Janer, dan Iman Paryudi, 2006, "Basis Data", Andi, Yogyakarta. 